\title{
Dwanaście lat Misyjnej Olimpiady Znajomości Afryki
}

„Afryka urzeka nas swoim pięknem, tajemniczością, egzotyką przyrody, odmienną kulturą. Jednakże większe wrażenie wywołują problemy, z którymi borykają się jej mieszkańcy. Głód, wojny, choroby, smutek i cierpienie dorosłych i dzieci - to zjawiska, których nie można pominąć, myśląc o Afryce" - tymi słowami prymas Polski kard. Józef Glemp w 2002 r. zachęcał w liście skierowanym do uczniów i nauczycieli do czynnego uczestnictwa w pierwszej edycji Misyjnej Olimpiady Znajomości Afryki, poświęconej przybliżaniu tego kontynentu młodym ludziom.

Inicjatorem powstania Misyjnej Olimpiady Znajomości Afryki był ks. dr Andrzej Halemba, sekretarz Komisji Episkopatu Polski ds. Misji w latach 1996-2003. Jego pomysł zyskał poparcie w środowisku naukowym UKSW, a szczególnie ówczesnego opiekuna Naukowego Koła Misjologów, ks. prof. dr. hab. Jarosława Różańskiego. Na wniosek Sekcji Misjologii Wydział Teologiczny powołał 7 listopada 2002 r. Misyjną Olimpiadę Znajomości Afryki oraz jej komitet główny, któremu powierzył całokształt spraw związanych z organizacją zawodów. Komitet główny opracował ogólną koncepcję wymagań stawianych olimpijczykom oraz przystąpił do organizacji zawodów. Pracami komitetu od momentu powstania Misyjnej Olimpiady Znajomości Afryki kieruje ks. prof. Jarosław Różański. Decyzją z dnia 2 lipca 2004 r. olimpiada ta zyskała aprobatę ministra edukacji narodowej i sportu.

Od samego początku wsparciem dla komitetu głównego były komitety okręgowe, których działa 16 . W trakcie dwunastoletniej historii ich siedziby zmieniały się, w chwili obecnej komitety okręgowe znajdują się w: Bydgoszczy (woj. kujawsko-pomorskie), Gorzowie Wlkp. (woj. lubuskie), Katowicach (woj. śląskie), Kielcach (woj. świętokrzyskie), Krakowie (woj. małopolskie), Lublinie (woj. lubelskie), Łodzi (woj. łódzkie), Łomży (woj. podlaskie), Olsztynie (woj. warmińsko-mazurskie), Opolu (woj. opolskie), Poznaniu 
(woj. wielkopolskie), Rzeszowie (woj. podkarpackie), Szczecinie (woj. zachodniopomorskie), Tczewie (woj. pomorskie), Warszawie (woj. mazowieckie) i Wrocławiu (woj. dolnośląskie).

Celem olimpiady jest promocja kontynentu afrykańskiego, zwrócenie szczególnej uwagi na działalność naszych rodaków, mianowicie bogactwo pracy polskich misjonarzy i misjonarek, ,ambasadorów” naszego kraju, oraz ludzi, wśród których żyją. Ponadto uczestnictwo w konkursie integruje uczniów wokół idei wychowania w duchu tolerancji, szacunku dla drugiego człowieka bez względu na jego pochodzenie oraz uczy wrażliwości, otwartości na inne narody i kultury.

W trakcie realizacji kolejnych edycji olimpiady omawiano następujące zagadnienia: rolę chrześcijaństwa w tworzeniu tożsamości afrykańskiej, fundamenty kulturowe Afryki, jedność i różnorodność kultur, przemiany ideowe, kształtowanie się narodów Afryki, ich wkład w historię, współistnienie i konflikty wewnątrzpaństwowe, wielokulturowość w dziejach Afryki, współistnienie religii i wyznań, znaczenie Kościoła katolickiego i wkład polskich misjonarzy, współczesne doktryny, ideologie i partie polityczne w Afryce, nierówności społeczne i ekonomiczne na kontynencie afrykańskim.

Do najważniejszych umiejętności zdobywanych przez uczniów, którzy biorą udział w Misyjnej Olimpiadzie Znajomości Afryki, należą: większa świadomość istnienia innych kultur (języków, zwyczajów, tradycji i systemu przekonań), otwartość, tolerancja, poszanowanie różnic kulturowych oraz wyrozumiałość i elastyczność. Uczniowie zyskują świadomość wartości swojej własnej kultury, jej oddziaływania na inne kultury, a jednocześnie uczą się doceniać różnorodność kulturową oraz stają się bardziej otwarci na różnorodność i zainteresowani nią.

Od początku, zgodnie z regulaminem olimpiady, prawo do udziału w niej przysługuje uczniom szkół ponadgimnazjalnych: liceów ogólnokształcących, liceów profilowanych, techników, uzupełniających liceów ogólnokształcących i zawodowych, techników uzupełniających, oraz uczniom ponadpodstawowych szkół średnich, ogólnokształcących i zawodowych. Co roku udział w olimpiadzie bierze ok. 200 szkół.

Misyjna Olimpiada Znajomości Afryki to zawody trójstopniowe o zasięgu ogólnopolskim: I stopień - etap szkolny, II stopień - etap okręgowy, III stopień - etap centralny.

Pierwszy etap olimpiady odbywa się w zgłoszonych do udziału w danej edycji szkołach. Zawody szkolne są przeprowadzane na początku grudnia. Uczestnicy etapu szkolnego mają za zadanie rozwiązać test składający się z 50 pytań jednokrotnego wyboru ${ }^{1}$.

${ }^{1} \mathrm{~W}$ pierwszej i drugiej edycji Olimpiady test etapu szkolnego składał się ze stu pytań. Od trzeciej edycji test składa się z pięćdziesięciu pytań. 
Do drugiego etapu przechodzi dwóch uczniów, którzy najlepiej wypełnili test w eliminacjach szkolnych. Etap okręgowy odbywa się zazwyczaj na przełomie lutego i marca. Jednostką, która zapewnia organizację tej części olimpiady, jest komitet okręgowy. W drugim etapie uczniowie mają za zadanie rozwiązać test, który składa się z 42 pytań testowych ${ }^{2}$, oraz udzielić pisemnej odpowiedzi na zaproponowany temat. Część pisemna testu sprawia uczniom najwięcej trudności, gdyż wymaga nie tylko zaprezentowania dokładnej wiedzy na zadany temat, ale także umiejętności przedstawienia jej $\mathrm{w}$ formie pisemnej. Dotychczas tematy prac pisemnych były następujące:

- I edycja (2002-2003) - Sformuluj krótka definicję pojęcia ,inkulturacja”, wyjaśnij ja oraz wypowiedz się na temat wptywu tego procesu na Kościót $i$ kultury w Afryce.

- II edycja (2003-2004) - Gtówne problemy szkolnictwa państwowego i wyznaniowego w Afryce subsaharyjskiej.

- III edycja (2004-2005) - Scharakteryzuj początki i rozwój misji polskich jezuitów w Zambii.

- IV edycja (2005-2006) - Scharakteryzuj promocję ludzka i jej formy pomocy $w$ rozwoju.

- V edycja (2006-2007) - Scharakteryzuj tradycyjne religie Afryki.

- VI edycja (2007-2008) - Scharakteryzuj jedna z pielgrzymek Jana Pawta II do Afryki: podróż Jana Pawła II do Beninu, 3-5 II 1993 r., lub podróż Jana Pawła II do Kamerunu, 14-16 IX 1995 r.

- VII edycja (2008-2009) - Przedstaw główne problemy poruszone przez Jana Pawła II podczas jednej z poniższych pielgrzymek: 1. Jan Pawet II w Angoli (4-5 i 7-10 VI 1992 r.); 2. Jan Pawet II w Czadzie (30 I - 1 II 1990 r.).

- VIII edycja (2009-2010) - Opisać jedna ze współczesnych form pomocy w rozwoju.

- IX edycja (2010-2011) - Scharakteryzuj pielgrzymkę Jana Pawła II do Zimbabwe w dniach 10-19 IX 1988 r.

- X edycja (2011-2012) - Scharakteryzuj pielgrzymkę Jana Pawła II do Tanzanii 1-5 IX $1990 \mathrm{r}$.

- XI edycja (2012-2013) - Kształcenie szkolne i zawodowe prowadzone w polskich misjach w poludniowej Afryce.

- XII edycja (2013-2014) - Scharakteryzuj ludy sawanny zachodnio-afrykańskiej na podstawie Z. Komorowski, ,Kultury Czarnej Afryki” (Wrocław 1994).

${ }^{2}$ Obecna liczba pytań testowych jest od VII edycji. W I edycji Olimpiady były 72 pytania, w II edycji 80 pytań, III-V edycji - 45 pytań, w VI edycji 44 pytania. 
Trzeci etap jest finałem olimpiady. Zgodnie z regulaminem kwalifikuje się do niego 35 osób, tj. 19 osób, które najlepiej napisały test w II etapie, oraz kolejna pierwsza osoba $\mathrm{z}$ okręgu. Założeniem organizatorów jest, aby każdy okręg miał swojego przedstawiciela $w$ finale ${ }^{3}$. Od początku istnienia olimpiady finał odbywa się w Auli Jana Pawła II na Uniwersytecie Kardynała Stefana Wyszyńskiego w Warszawie. W latach 2005-2013 etap centralny, dzięki dofinansowaniu z Ministerstwa Edukacji Narodowej, był podzielony na dwa dni. W pierwszym były przeprowadzane zawody wyłaniające zwycięzcę olimpiady. Drugiego dnia uczestnicy finału wraz z opiekunami zwiedzali jedno z muzeów w Warszawie (były to m.in. Muzeum Etnograficzne, Muzeum Narodowe, Muzeum Powstania Warszawskiego, Pałac i Ogród w Wilanowie, Muzeum bł. ks. Jerzego Popiełuszki). Status laureata Misyjnej Olimpiady Znajomości Afryki uzyskuje 15 finalistów, którzy w części pisemnej otrzymali największą liczbę punktów. Do części ustnej etapu centralnego, mającej wyłonić zwycięzcę olimpiady, kwalifikuje się pięciu laureatów z najwyższą liczbą punktów. Zwycięzcą Misyjnej Olimpiady Znajomości Afryki zostaje uczeń, który łącznie w części ustnej i pisemnej etapu centralnego uzyska najwyższą liczbę punktów. Nad prawidłowym przebiegiem finału czuwa komisja złożona z ekspertów: profesorów i znawców z dziedziny misjologii i afrykanistyki. Dotychczas zwycięzcami kolejnych edycji zostali:

\begin{tabular}{|c|l|l|}
\hline Edycja & \multicolumn{1}{|c|}{ Imię i nazwisko } & \multicolumn{1}{|c|}{ Szkoła } \\
\hline I & Grzegorz Węglarz & LO im. Bolesława Chrobrego w Bielawie \\
\hline II & Renata Bielawska & LO im. mjra Henryka Sucharskiego w Krzyżu Wlkp. \\
\hline III & Karolina Bugajska & I LO im. Władysława Orkana w Limanowej \\
\hline IV & Alicja Kalinowska & $\begin{array}{l}\text { II LO im. Konstantego Ildefonsa Gałczyńskiego } \\
\text { w Olsztynie }\end{array}$ \\
\hline V & Małgorzata Filip & LO im. Komisji Edukacji Narodowej w Stalowej Woli \\
\hline VI & Jan Dąbrowski & $\begin{array}{l}\text { II LO im. Stefana Żeromskiego } \\
\text { w Tomaszowie Mazowieckim }\end{array}$ \\
\hline VII & Adrian Moskal & LO im. Komisji Edukacji Narodowej w Stalowej Woli \\
\hline VIII & Ewa Wójcik & I LO im. Juliusza Słowackiego w Częstochowie \\
\hline
\end{tabular}

${ }^{3}$ Liczba uczniów zakwalifikowanych do finału w poprzednich edycjach była zmienna. W pierwszych edycjach zgodnie z ówczesnym regulaminem Olimpiady do finału kwalifikowano trzech najlepszych uczniów z każdego okręgu. Na przestrzeni lat, zwykle do finału kwalifikowało się ok. 50 uczniów. Rekordowo duża liczba uczestników w finale była w VII edycji - 61 uczniów. 


\begin{tabular}{|c|l|l|}
\hline Edycja & \multicolumn{1}{|c|}{ Imię i nazwisko } & \multicolumn{1}{c|}{ Szkoła } \\
\hline IX & Sabina Sy & V LO im. Augusta Witkowskiego w Krakowie \\
\hline X & Anna Majewska & $\begin{array}{l}\text { II LO im. księżnej Anny z Sapiehów Jabłonowskiej } \\
\text { w Białymstoku }\end{array}$ \\
\hline XI & Magdalena Chmura & LO im. Bolesława Chrobrego w Głuchołazach \\
\hline XII & Justyna Różycka & $\begin{array}{l}\text { Publiczne LO im. Jana Pawła II Sióstr Prezentek } \\
\text { w Rzeszowie }\end{array}$ \\
\hline
\end{tabular}

Każdego roku finał olimpiady uświetnia zespół Bongo-Bongo. Pochodzący z Konga lider zespołu Ricky Lion wprowadza swoją muzyką wszystkich uczestników oraz zaproszonych gości w afrykańskie klimaty. Ważnym akcentem każdego finału są także zaproszeni goście. Poza przedstawicielami instytucji misyjnych oraz rządowych są wśród nich m.in. pracownicy ambasad krajów afrykańskich, które mają swoje przedstawicielstwa w Polsce.

Od samego początku organizatorzy dokładali wszelkich starań, aby za trud, jaki uczniowie ponosili w przygotowaniach do poszczególnych etapów olimpiady, byli nagradzani atrakcyjnymi nagrodami. W pierwszych edycjach główną nagrodę stanowiła m.in. wycieczka do Afryki lub Rzymu, a także uczestnictwo w wakacjach z misjami w Ocyplu k. Starogardu Gdańskiego, pobyt w ośrodku wypoczynkowym „Caritas” Wojska Polskiego w Ustce, tygodniowy pobyt w okresie wakacyjnym w ośrodku wypoczynkowym „Bursztyn" w Krynicy Morskiej, w Domu Misyjnym w Jastrzębiej Górze, wycieczka „Śladami cystersów po Wielkopolsce i Pomorzu Zachodnim”, zorganizowana przez Biuro Pielgrzymkowe Księży Pallotynów w Warszawie. Bardzo atrakcyjną nagrodą był też wywiad ze zwycięzcą w jednym z programów TVP. Choć wymienione nagrody można uznać za atrakcyjne, to jednak dla finalistów olimpiady najcenniejszą i zarazem najważniejszą nagrodą jest indeks na wymarzony kierunek studiów. Laureaci i finaliści olimpiady mogą być zwolnieni w części lub w całości z egzaminów wstępnych do szkół wyższych na kierunek zgodny z profilem olimpiady.

Organizatorzy wkładają wiele wysiłku, aby uczniowie, którzy biorą udział w Misyjnej Olimpiadzie Znajomości Afryki, czuli się jak w jednej wielkiej wspólnocie misyjnej. Jako organizatorzy mamy nadzieję, że wysiłek ten wyda owoce przejawiające się w większej wrażliwości jej młodych uczestników na potrzeby drugiego człowieka, w misyjnym ich zaangażowaniu. Może niektórych zaprowadzi do decyzji podjęcia służby misyjnej ad gentes. 


\title{
12 YEARS OF THE HIGH SCHOOL CONTEST ON THE KNOWLEDGE OF AFRICA
}

\begin{abstract}
SUMMARY
The article summarizes the short story of a particular scholarly contest addressed to the high school students in Poland. Its theme is the general knowledge of the African continent, from the cultural, sociological, economical, historical and religious point of view. Each edition of the contest had its leading subject. The event met over the past 12 years with great interest among young students across the country and at its central stage in Warsaw was accompanied by various cultural activities aimed at better acquaintance with the richness of the African cultures.
\end{abstract}

Keywords: Africa, missiology, popularization of other cultures, high school creative education

Słowa kluczowe: Afryka, misjologia, popularyzacja kultur, twórcza edukacja na poziomie średnim

DR KINGa PUChatA - w 2012 r. obroniła dystertację doktorską na Uniwersytecie Kardynała Stefana Wyszyńskiego w Warszawie pt. Rola Rzymianek w starożytnej chrystianizacji (I-V w.) na podstawie literatury patrystycznej i wspótczesnej, współorganizatorka Misyjnej Olimpiady Znajomości Afryki. 